\title{
Effect of Self Care Interventions on the Quality of Life of Older Adults with
}

\section{Heart Failure}

\author{
Samia El Husseini Abd El Mageed, Assistant Lecturer \\ Gerontological Nursing, Faculty of Nursing, Alexandria University \\ Rasha Ahmed Fouad, Assistant Professor \\ Gerontological Nursing, Faculty of Nursing, Alexandria University \\ Nagwa Abd El Fattah Ibrahim, Professor \\ Gerontological Nursing, Faculty of Nursing, Alexandria University
}

\begin{abstract}
Heart failure self care refers to the practices in which geriatric patients with heart failure engage in their own care to maintain their own health, and their decisions about managing signs or symptoms. Objective: The study was conducted to determine the effect of self-care interventions on quality of life $(Q O L)$ of older adults with heart failure. Setting: The study was carried out in the outpatient cardiac clinic in the health insurance hospital (Gamal Abd El Naser), Alexandria, Egypt. Subjects: The study subjects included, thirty older adults diagnosed with HF for at least 6 months. Tools: Seven measures were used in this study; the socio-demographic and clinical data structured interview questionnaire, New York Heart Association Functional Classification (NYHA), Mini-Mental State Examination (MMSE) Scale, Geriatric Depression Scale-Short Form (GDS-SF), Minnesota living with heart failure questionnaire(MLHFQ), European Heart Failure Self-Care Behavior Scale (EHFSCBS), and Dutch Heart Failure Knowledge Scale (DHFKS). Results: There are significant improvements in both quality of life and self care practice and knowledge after the implementation of the interventions which decreased gradually 6 weeks and 12 weeks later. However, they still better than before the interventions. Conclusion: Implementation of the self-care interventions proved to be effective in improving self-care knowledge, self-care practices and health related QOL for the majority of the study older adults. Recommendations: Preparation of an instructional booklet to include the self care interventions for older adults with heart failure. Further researches are needed such as: Effectiveness of nursing intervention strategies on the QOL of older adults with HF.
\end{abstract}

Keywords: Older adults; Heart failure; Self care; Quality of life; Nurses' role.

\section{Introduction}

Heart failure (HF) is one of the most prevalent cardiovascular disorders. HF has become a significant public health problem due to the rapidly increasing incidence and prevalence that is predicted to continue to grow far into the $21^{\text {st }}$ century. Overall, 1$2 \%$ of the adult people in developed countries worldwide suffer from HF but this prevalence increases 10 -fold in individuals over 75 years of age ${ }^{(1,2)}$. HF is mainly a 'disease of old age persons' affecting approximately $7 \%$ of those aged 75-84 years and $15 \%$ of those aged 85 years and older and it is among the peak five reasons for medical consultations among males more than 75 years and among females more than 85 years. Therefore, HF is considered a major cause of morbidity and represents one of the most costly conditions for the National Health Service to manage ${ }^{(2,3)}$.

In Egypt, HF is the leading cause of hospitalization for those over the age of 65 and represents a significant clinical and economic burden. It is expected that the prevalence of HF will nearly double over the coming 40 years. The important causes for this high prevalence and for the increasing incidence of HF especially in the past decades and possibly in the coming 
years are that, HF is generally a disease of old age with the increase in the average life expectancy and aging of population all over the world. The average life span in Egypt is increased by about 15 years in the previous three decades (average life expectancy increased from 54 to 69 years). In addition to, the rising incidence of diabetes mellitus, an important risk factor for atherosclerotic cardiovascular disease and for HF. Moreover, Improvement in survival of patients with coronary artery disease, valvular and hypertensive heart disease due to the foundation of proper and effective surgical and pharmacologic treatments. These modern therapies are effective in improving symptoms, morbidity and mortality, allow patients to live longer with poor cardiac function and in the majority of cases they only delay the development of $\mathrm{HF}^{(4)}$.

$\mathrm{HF}$ is associated with a poor prognosis, with symptoms affecting daily living activities, and a treatment regimen that can have a major impact on the daily life of older adults and their families ${ }^{(4)}$. HF elders' group is representative of the growing segment of the population living longer with chronic health problems and experiencing breakdowns in care during multiple transitions from hospital to home that unfortunately affect negatively their QOL and consume substantial healthcare resources. Similar to most chronically ill elders, these patients typically have multiple co-morbid medical conditions, more disabling symptoms, complex medication regimens, and limited self-management skills. One study did examine the QOL within a community based sample of 426 older adults with HF, identifying statistically significant impairments in all domains of $\mathrm{QOL}^{(5)}$.

It is generally recognized that the treatment of older adult patients with $\mathrm{HF}$ has only two main objectives: first to improve the QOL and second to prolong life $^{(6)}$. QOL is increasingly being incorporated in large clinical trials as a complementary endpoint to the traditional outcomes of mortality and morbidity, given that the prognosis in HF is worse than in either breast or prostate cancer ${ }^{(7)}$. Indeed, the older adults with $\mathrm{HF}$ place a high priority on QOL. The healthcare system has traditionally focused on treating disease at point of failure, such as life-saving surgery or intensive medical therapy. As demographics shifts more to an aging population, management of health-related QOL and life-restricting disease becomes more necessary. Prominent among such diseases is congestive heart failure (CHF), which must be considered as a main community health problem with its resultant effect on QOL ${ }^{(6)}$.

In HF, self-care refers to the behaviors developed by elderly persons to maintain their health (self-care maintenance) and decisions they make about worsening of symptoms when they occur (self-care management). The self-care maintenance involves adherence to the treatment regimen, consumption of a lowsalt diet, cessation of smoking, and daily monitoring of body weight, signs or symptoms, Self-care management is an active, deliberate process that begins with recognizing a change in signs or symptoms, evaluating the change, deciding to take action, implementing a treatment strategy, and evaluating the treatment implemented. From this perspective, self-care is a decision-making process that elderly persons use in choosing behaviors that maintain physiological stability and response to the symptoms when they $\operatorname{occur}^{(8,9)}$.

Self-care behavior is well known to achieve the best possible health outcomes, prevent serious complications and consequences, and reduce the mortality rates among older adults with $\mathrm{HF}^{(10)}$. However, many older adults with HF have inadequate self-care behaviors. Self-care behaviors among older adults with HF have been reported to be complex and difficult for them since older adults must adhere to symptom monitoring, and treatment regimens $^{(11)}$. One reason may be that the 
elderly have multiple age-associated changes inmost organ systems such as cardiovascular, respiration, digestion, vision, hearing, etc. In addition to complexity of HF treatment regimens, most of older adult patients also have many comorbid diseases ${ }^{(12)}$. Non-adherence to medication and lifestyle change are other major problems in older adults with HF ${ }^{(10)}$.Poor self-care behaviors with lack of adherence to a HF regimen lead to $20-60 \%$ of $\mathrm{HF}$ rehospitalization which will affect their QOL ${ }^{(11,12)}$.

Maximizing QOL for older adults with $\mathrm{HF}$ has been identified as a key challenge for clinicians involved in the care of elderly persons ${ }^{(13)}$. So, the gerontological nurse have a vital role in increasing the elders' sense of control, allowing the greatest potential for independence and selfdirection in daily activities, promoting social involvement and greater sense of involvement in their care and a greater level of adjustments and QOL ${ }^{(14)}$.

Self-care for elders with $\mathrm{HF}$ is challenging. Although predictions that better self-care can positively influence QOL, there is a lack of data supporting this assumption. Further investigations and studies may help to identify those susceptible to a diminished QOL, due to lack of ability to integrate self-care in the management of their $\mathrm{HF}^{(11,15)}$.

\section{Aim of the Study}

The aim of this study is to determine the effect of self-care interventions on the quality of life of older adults with HF.

\section{Research Hypothesis:}

Older adults with HF who receive the proposed self-care interventions exhibit higher quality of life post the interventions than before it.

\section{Materials and Method}

Materials

Design: The study followed a preexperimental design.

Setting: The study was carried out in the outpatient cardiac clinic in the Health Insurance Hospital (Gamal Abd El Naser), Alexandria, Egypt.

Subjects: The study subjects included, thirty older adults diagnosed with $\mathrm{HF}$ for at least 6 months, aged 60 years and above, classified as first, second, or third class HF (NYHA classification of HF), able to read and write, have normal cognitive function (score 24 and more on the Mini Mental State Examination Scale (MMSE), have no depression (score 0 to 4 on the Geriatric Depression Scale-Short Form (GDS-SF), accept to participate in the study.

Tools: Seven tools were study to collect the necessary data:

Tool I: Socio-demographic and clinical data structured interview schedule

It was developed by the researchers based on relevant literature to collect information from the study subjects about socio-demographic data of the elders and medical health history such as onset and duration of HF, and treatment regimen, the presence of other medical problems, medications, and number and reason of previous hospitalization in the last year. In addition to emotional health status.

Tool II: New York Heart Association Functional Classification (NYHA)

The New York Heart Association Functional Classification (NYHA) ${ }^{(16)}$ provides a simple way of classifying the extent of HF. It places patients in one of four categories based on how much they are limited during physical activity. Class I: patients with no limitation of activities; they suffer no symptoms from ordinary activities. Class II: patients with slight, mild limitation of activity; they are comfortable with rest or with mild exertion. 
Class III: patients with marked limitation of activity; they are comfortable only at rest. Class IV: patients who should be at complete rest, confined to bed or chair; any physical activity brings on discomfort and symptoms occur at rest.

\section{Tool III: Mini-Mental State Examination (MMSE) Scale}

It was developed by Folestein et al. $(1975)^{(17)}$ and used to assess cognitive function of the study subjects. It includes questions related to orientation, registration, attention and calculation, recall, and language. The MMS scale score is 30 point and is classified as follows:-Score of 24-30 indicates normal cognitive function, Score of 18-23 indicates mild cognitive impairment of the elderly, Score of 0-17 indicates severe cognitive impairment of the elderly. The MMS was translated into Arabic and approved to be valid and reliable by Elhusseini $(2008)^{(18)}$. The Arabic version of this scale was used in this study.

\section{Tool IV: Geriatric Depression Scale- Short Form (GDS-SF)}

It is a 15-item self-report instrument developed by Yesavage et al. (1983) ${ }^{(19)}$ to assess depression and general well-being in the elderly. Scores range from 0 to 15 and a score from 0 to 4 indicate no depression, 5 to 8 mild depression, 9 to 11 moderate depression, and 12-15 severe depression.

\section{Tool V: Minnesota Living with HF questionnaire (MLHFQ)}

It is a quality of life (QOL) instrument specifically for HF patients ${ }^{(20)}$. This questionnaire consists of 21 questions. Persons respond to each question using a 6point Likert-type scale where 0 equals no times, 1 equals very little times, and 5 equals very much times.

\section{Tool VI: European HF Self-Care Behaviour Scale (EHFSCBS)}

It was developed by Jaarsma et al. $(2003)^{(21)}$. It is a 12-item, self-administered questionnaire that covers items concerning self-care behavior of patients with $\mathrm{HF}$. The response to each item scored on a 5-point
Likert scale from 1 "I completely agree" to 5 "I do not agree at all." The total score is calculated by summing the ratings for each item and can range from 12 to 60 . Higher scores indicate poorer self-care behavior.

Tool VII: Dutch HF Knowledge Scale $\underline{\text { (DHFKS) }}$

It is a 15 item multiple choice selfadministered questionnaire on knowledge of patients with HF. This tool was developed by Vander Wal et al. (2005) ${ }^{(22)}$. For each item, patients choose from three possible answers, one of which is the correct answer. Respondents receive one point for a correct answer and zero point for an incorrect or missing answer. The maximum score possible is 15 , which indicates that all items were answered correct.

\section{Method}

- An official letter was issued from the Faculty of Nursing, Alexandria University to the Health Insurance Commission in Alexandria to obtain permission to attend the cardiac outpatient clinic (Gamal Abd ElNaser) in Alexandria for data collection. Permission from the heads of the study settings was obtained, who were informed about the purpose of the study and the date and time of data collection.

- The Arabic version of tool two (NYHA), and three (MMSE) was used in this study, and tools from four to seven were adapted and translated into Arabic and were tested for content validity by seven experts in the related fields. These tools were tested for reliability using Cronbach's coefficient Alpha, and were applied to 10 older adults with HF selected from the health insurance hospital (outpatient medical clinic) in Alexandria, the results were as follows: tool four (0.07), tool five (0.921), tool six (0.758), and tool seven (0.72).

- A pilot study was carried out on five older adults with HF selected from the health insurance hospital (outpatient 
medical clinic) in Alexandria to test clarity, feasibility and the applicability of the tools.

- Self care interventions were developed by the researchers based on reviewing the related literature. It covered items related to knowledge and skills required for self-care of older adults with HF. The interventions were prepared and divided into ten sessions. After ensuring the diagnosis of HF from the attending physician, each study subject was interviewed individually in the cardiac outpatient clinic. The researchers conducted from four to six sessions per day. The sessions were conducted two times for two groups and it was covered for each group in five weeks. The first group included 18 patients, and the second group included 12 patients.

- The researchers started each session by reemphasizing the important points in the previous session. During each session, flip chart (contain illustrative pictures and the main points according to the content of each session) that was developed by the researchers was used in order to clarify the desired knowledge, and skills for each elder. Other teaching methods used were open discussion, demonstration, redemonstration and real life situation. The researchers formulated an action plan calendar with goals based on the needs and the abilities of each study subject after each session. Along with all sessions, the researchers reviewed the action plan calendar to assess the older adult's commitment with the plan. At the end of the session, the researchers and the older adult evaluated the preset goals through selfcare goal tracking form giving score for the older adult's achievement. The researchers maintained study subjects' motivation and giving positive feedback and reinforcement.

- Reassessment of each study subject was done three times to evaluate the effect of the self-care interventions on histherself-care knowledge, practices and QOL. This was done immediately after the implementation of the interventions, then the second reassessment after six weeks, followed by the third assessment after another six weeks. The evaluation of the effectiveness of the proposed self-care interventions was determined by using the proper statistical analysis. The data collection and implementation of the program took six months started from the beginning of April until the end of September 2012.

\section{Ethical considerations:}

An informed written consent was obtained from each study subject included in this study after explanation of the study purpose. Anonymity and privacy of the study subjects, confidentiality of the collected data and the subject's right to withdraw at any time was maintained.

\section{Statistical Analysis}

The SPSS V 19.0 was used for the analysis of the data. Reliability of the tool was determined by Cronbach alpha. Quantitative data were summarized by the arithmetic mean and standard deviation. Comparison of means was done by Student t-test and One-Way Analysis of Variance (ANOVA). $\quad \mathrm{T} 1=$ the difference between pretest and immediate post test, $\mathrm{T} 2=$ the difference between $6 \mathrm{w}$ posttest and immediate post test, T3=the difference between $12 \mathrm{w}$ posttest and immediate post test, $\mathrm{T} 4=$ the difference between pretest and $12 \mathrm{w}$ post test, X21: the difference between pretest, immediate posttest and 6 weeks posttest. X22: the difference between pretest, immediate posttest, 6 weeks posttest, and 12 weeks posttest. Pearson's Correlation Coefficient was also used.

\section{Results}

Table (1) shows the relation between the QOL of the study subjects and their socio-demographic characteristics prior to 
the interventions. The table illustrates that the highest mean score $(41.00 \pm 11.34)$ of total QOL is obtained by older adults (70 years and more) Regarding sex, although higher level of QOL is obtained by males than females $(38.09 \pm 12.94,38.63+10.239$ respectively), the variance is not statistically significant (0.917). The lowest QOL mean score $(36.69 \pm 8.29)$ and $(37.43 \pm 16.30)$ are obtained by higher level of education (secondary and university respectively), the study subject with monthly income 1000 LE and more reported higher QOL $(35.88 \pm 15.05)$ than those with income less than 500 LE/month $(38.33 \pm 6.60)$. The difference is not statistically significant (0.811).

Table (2) shows the relation between the QOL, self-care knowledge, and self-care practice of the study subjects prior to the interventions. A positive significant relation is observed between the QOL and self-care practices of the study subjects (0.004). While, the relation between the QOL and the self-care knowledge of the study subjects is positive but not statistically significant (0.9730). Moreover, there is a positive relation between self-care practices and the self-care knowledge of the study subjects.

Table (3) shows the effect of self-care interventions on the mean QOL of older adults with HF. Immediately after the study interventions, high level of QOL is reported $(25.80 \pm 9.038)$ in comparison to its level prior the interventions $(38.23 \pm 12.111)$. The difference is statistically significant $(0.000)$.

After six weeks from the end of the study interventions, QOL is decreased $(28.13 \pm 8.541)$ in comparison to its level immediately after it with no significant difference (0.359). The difference in the levels of QOL of the study subjects before the study interventions, immediately after the interventions, and after 6 weeks from the interventions is statistically significant (0.000).

After 12 weeks, further decrease in QOL is observed $(33.97 \pm 8.892)$ in comparison to its level immediately after the interventions and the difference is highly statistically significant (0.000). The difference in the levels of QOL of the study subjects before the study interventions, immediately after the interventions, after 6 weeks, and after 12 weeks from the interventions is statistically significant (0.000).

Furthermore, QOL of the study subjects after 12 weeks $(33.97 \pm 8.892)$ is still higher than its level before the study interventions $(38.23 \pm 12.111) \quad$ with a statistically significant difference (0.001).

Table (4) shows the effect of self-care interventions on the mean self-care practice of older adults with HF. Immediately after the study interventions, self-care practices improved $(18.20 \pm 2.413)$ in comparison to its level prior the interventions $(10.20 \pm 3.326)$ with statistically significant difference $(0.000)$.

After six weeks from the end of the study interventions, main self-care practice decreased $(17.83 \pm 2.71)$ in comparison to its level immediately after the interventions but the difference is not statistically significant (0.535). The difference between pretest, immediately posttest, and after 6 weeks posttest is statistically significant (0.000).

After 12 weeks, self-care practices mean score decreased again $(13.70 \pm 2.842)$ in comparison to its level immediately after the interventions and the difference is statistically significant (0.000). The difference in the levels of self-care of the study subjects before the study interventions, immediately after the interventions, after 6 weeks, and after 12 weeks from the interventions is statistically significant (0.000).

Furthermore, mean self-care practice of the study subjects after 12 weeks $(13.70 \pm 2.842)$ is still higher than its level before the interventions $(10.20 \pm 3.326)$ with a statistically significant difference (0.000).

Table (5) shows the effect of self-care interventions on the mean self-care knowledge of older adults with HF. Immediately after the interventions, mean self-care knowledge improved $(9.01 \pm 1.179)$ 
in comparison to its level prior the interventions $(5.23+1.25)$. However, the difference did not reach to a statistically significant level (0.072).

After six weeks from the end of the interventions, mean self-care knowledge is decreased $(8.07 \pm 1.251)$ in comparisons with its level immediately after the interventions with no statistically significant difference (0.178). The difference between pretest, immediately posttest, and after 6 weeks posttest is not statistically significant (0.213).

After 12 weeks, self-care knowledge mean score decreased again $(5.70 \pm 1.69)$ in comparison to its level immediately after the end of the interventions with no statistically significant difference (0.79). The difference between pretest, immediately posttest, after 6 weeks posttest, and after 12 weeks posttest is not statistically significant $(0.114)$.

Furthermore, mean self-care knowledge of the study subjects after 12 weeks $(5.70 \pm 1.69)$ is still slightly higher than its level before the interventions $(5.23 \pm 1.25)$. However, the difference does not reach to statistically significant level (0.192).

Table (6) shows the effect of the selfcare interventions on mean QOL and health status of the study subjects. High mean QOL of older adults with $\mathrm{HF}$ $(34.50 \pm 12.655)$ is associated with being diagnosed with $\mathrm{HF}$ for less than 5 years prior to the study interventions and the difference is statistically significant (0.038). This difference as evidenced by $\mathrm{P}$ value decreased (0.248) immediately after the implementation of the interventions, and after 6 weeks (0.652), and then return to rise again after 12 weeks $(0.153)$ from the end of the study interventions. The degree of difference among different classes of $\mathrm{HF}$ regarding QOL is decreased immediately after the implementation of the interventions (0.001) and after 6 weeks (0.759), then return to rise again and 12 weeks (0.001) from the end of the interventions. Increased the number of comorbidities other than HF that the study subjects have (4 and more) is associated with lower QOL $(49.51 \pm 11.50)$ prior to the interventions. This difference decreased immediately after the implementation of the study interventions (0.141) and after 6 weeks (0.535), and then return to rise again after 12 weeks $(0.093)$ from the end of the interventions.

Table (7) shows effect of the self-care interventions on the relation between the QOL and the self-care knowledge and practice of the study subjects. The table a positive significant relation between the QOL and the self-care practices of the study subjects prior to the interventions (0.004). It is observed that the degree of the relation between QOL and self-care practices as evidenced by $P$ value decreased immediately after the implementation of the interventions (0.415) and then return to rise again after 6 weeks $(0.365)$ and after 12 weeks (0.015) from the end of the interventions.

Although the relation between the QOL and the self-care knowledge of the study subjects is not statistically significant prior to the interventions (0.973), it is observed that the strength of the relation as evidenced by $\mathrm{P}$ value is increased immediately after the implementation of the interventions (Pearson correlation $=0.389, \mathrm{P}=0.341$ ) and after 6 weeks $(=0.291)$, and then return to drop again after 12 weeks $(0.717)$ from the end of the interventions.

\section{Discussion}

QOL of older adults with HF is noticeably compromised, and closely related to poor clinical outcomes such as rehospitalization and mortality, thus appropriate assessment of QOL should be done when patients with HF are first diagnosed and throughout the course of this chronic illness ${ }^{(23-27)}$.

Results of the present study revealed that high QOL was reported by young older adults prior to the study interventions. This may be due to the fact that advancing age is associated with multiple changes as 
physiological, psychological and social difficulties which affect the daily lives of patients with HF. Thus aging changes and chronic illnesses decrease the functional abilities of the older adults and limit the selection of physical activity in which they engage. Consequently, these limitations will hinder their self-care practices which in turn will negatively affect their health outcomes and QOL. These results are in line with the findings reported by other studies ${ }^{(28,29)}$. In contrast, Zambroski et al. (2005) $)^{(30)}$ found that young older adults with HF who had low physical functioning and great symptoms burden reported poor QOL.QOL of subjects in the three age groups has improved immediately after the present study interventions (table 1). This finding showed that age, as a variable don't have any specific relation on QOL.

In respect to sex, the present study showed no statistically significant difference was found between the QOL and the sex (table 1). However, it is observed that females have a slightly higher mean score which indicate poorer QOL than males. This may be due to the increased incidence of chronic illnesses among females than males which adds more stressors and complains among females. This result is in agreement with what was reported by Hou et al. $2004^{(31)}$. In contrast, De Jong et al. $(2006)^{(32)}$ reported no difference between men and women in their QOL.

In this study, married elders reported slightly better QOL than widows (table 1). This may be related to the fact that, the loss of spouse can be disruptive to the survivor's self-care and health promotion practices, especially for those who lack the knowledge and skills to successfully engage in those behaviors $^{(33)}$. A widow elder man may not be able to cook and provide an adequate diet for himself because he has been always dependent on his wife for meal preparation $^{(34)}$. As a result, the disease management will be provided in a poor quality with poor outcome which will negatively affect the QOL of older adults.
Antinian et al. (2002) investigated the selfcare behaviors among patients with HF and their reported results are in line with the finding of the present study regarding the $\mathrm{QOL}^{(35)}$.

With regard to education, patients with secondary school education or higher reported higher level of QOL than those with lower education (table 1), however, this can be justified by the fact that, the lack of education will result in ignorance about good health practices, lack of information about health and illnesses, and elders will not be able to explain or demonstrate essential skills for self-care or health maintenance. Furthermore, education helps elders to view their abilities without overestimating or underestimating, and help them to acquire sense of control over their environment. Moreover, highly educated elders are welcomed to use more advanced practices and be educated about different lines of treatment which has proven to subside greatly their complaints and stressors to a satisfactory degree than others. These findings are in supports with the results reported by Lee et al. (2005) ${ }^{(36)}$.

As for the monthly income, higher income of patients was found to be associated with higher level of QOL. This may be related to the association between educational opportunities and increased income $^{(37)}$. Moreover, lack of financial resources affect the quality of nutrition, social activities, acquisition of needed medical care and therapeutic regimen. This result is congruent with that of another study which reported that QOL of patients with HF is correlated with better economic status $^{(38)}$.

Self-care practice of the study subjects is significantly related to the QOL, the present study subjects with higher level of self-care practice, reported higher level of QOL than those with lower level of selfcare practice. This may be explained by the fact that, practicing self-management can empower the individual to cope with the disease and maintenance of QOL with the fewer restrictions caused through their 
illnesses by developing self-efficacy, which is the level of confidence that an individual has in his or her ability to succeed in dealing with their own chronic disease ${ }^{(39,40)}$. This finding is in accordance with what was reported by Carlson et al. $(2001)^{(41)}$.

Regarding self care knowledge, the study subjects with higher level of self-care knowledge, reported higher level of QOL than those with poor self-care knowledge prior to the implementation of the study interventions. This may be due to the fact that the physical and psychological process of HF causes serious disruption in self-care for individuals with $\mathrm{HF}$ which affect the individual perception of QOL. This finding supports those of studies which reported that strong relations exist between the QOL and the self-care knowledge of older adults with $\mathrm{HF}^{(42,43)}$. Thus, the high the self care knowledge, the better the QOL. Individuals with HF seek to meet their self-care demands and increase self-care abilities by developing knowledge and skills for selfcare. By applying this knowledge, individuals with HF learn to perform effective self-care, which may theoretically improve their $\mathrm{QOL}^{(44)}$.

The results of the present study also showed that the study subjects with higher level of self-care knowledge, reported higher level of self-care practice. However, the relation between self-care knowledge and self-care practice did not reach a significant level. This may be due to the fact that, the ability to recognize $\mathrm{HF}$ symptoms and to rate their importance are fundamental to the self-care of older adults with HF. The recognition of symptoms and their importance enables the patients to be able to evaluate what course of action to take. This finding supports other studies carried out by Driscoll et al. (2009), and Ni et al. (1999) who investigated consumer resources to enhance self-care in chronic $\mathrm{HF}$ and factors influencing knowledge of and adherence to self-care among patients with $\mathrm{HF}^{(45,46)}$. In this regard, Artinian et al. (2002) indicated that self-care knowledge deficit was related to inability to do self- care and the knowledge is necessary but not sufficient, for self-care ${ }^{(35)}$. Moreover, Carlson et al. (2001) reported that education and experience could enhance the self-care abilities of patients with HF. However, some patients are still lacking selfconfidence to take the appropriate action ${ }^{(41)}$.

In the present study, self-care interventions resulted in significant increase in the self-care practice and better QOL of the study subjects, self-care interventions improved self-care knowledge than before the implementation of the interventions. These improvements in the self-care practice, self-care knowledge, and the QOL of the study subjects may be related to the availability \& the implementation a written action plan for self-care practice $\&$ the provision of hand out to elders. Moreover, the study patients who practice effective self-care management can easily recognize the changes, act to ameliorate symptoms by limiting fluid or sodium intake, or taking additional doses of low-dose diuretics as a treatment strategy, and evaluate its effectiveness which leads to better outcomes. In addition, effective self-care is complementary to optimal medical management in delaying $\mathrm{HF}$ progression and complications and thus it is considered a cardio protective approach ${ }^{(46,47)}$. This finding is consistent with that of other several studies Gaze $(2007)^{(47)}$ who reported that, effective self-care management programs are considered successful approaches to improve the QOL of patients with HF. Moreover, Yu et al. (2006) ${ }^{(48)}$ reported in a meta-analysis of 21 RCTs of the HF disease management programs, were found to be effective in reducing rehospitalization or mortality and improving the QOL in older adults with HF when these programs included a flexible, individualized approach; promotion of self-care and optimizing of medical therapy. HF Society of America (HFSA) (2006) ${ }^{(49)}$ reported that, strategies that aimed to increase self-care abilities of cardiac patients improved the patients' knowledge, skills, adherence and clinical outcomes. As a result, they recommended promotion of self-care as the 
basic care model. Kutzleb et al. (2006) ${ }^{(50)}$ concluded that a nurse- directed patient selfcare education treatment strategy for patients with HF significantly improves the patients' role in symptoms control and disease self-management. Moreover, Haynes et al. $(2005)^{(51)}$ demonstrated that the nurse-directed patient education was effective for improving patients' self-care and the QOL.

These changes that occur in the levels of self-care practice, self-care knowledge, and QOL in the present study with the passage of time are consistent with the findings of another study ${ }^{(52)}$. However, the present study suggests that, learned behaviors change over time and the duration of contact time between the educator and the patient was the only significant predictor due to several reasons. First; educationally, it can be interpreted by what was reported by Geoffrey (1985), forgetting curve hypothesizes the decline of memory retention in time. This curve shows how information is lost over time when there is no attempt to retain them, the stronger the memory, the longer the period of time that a person is able to recall it. A typical graph of the forgetting curve purports to show that humans tend to halve their memory of newly learned knowledge in a matter of days or weeks unless they consciously review the learned material ${ }^{(53)}$. Second; decrease frequent contact between the researchers in this study and the patients after the interventions to follow the elder's achievement and commitment of the action plan, third; normal age related changes that may include memory changes, and reduction of the attention and retention span of the older adults. Finally, the fourth reason may be the decrease in the elders' reinforcement and motivation to comply with the action plan. According to the results of this study, the proposed hypothesis is approved, older adults with $\mathrm{HF}$ who received self-care interventions reported higher self-care knowledge, selfcare practice, and QOL.

\section{Conclusion}

Based on the results of the current study, it can be concluded that implementation of the self-care interventions proved to be effective in improving self-care knowledge, self-care practices and health related QOL for the majority of the study older adults. Although this improved have decreased over time, however, it still remains better than before the interventions.

\section{Recommendations}

Based on the findings of this study, the following recommendations are suggested:

- Faculty members of the gerontological nursing department should conduct the following:

- Development of skill- based training program for nurses in the outpatient clinics. The program includes knowledge and practices of self-management of HF in older adults.

- Developing an educational program for older adults with $\mathrm{HF}$ who attend the outpatient clinics and their principle support persons (care givers) on the role of the older adults in the management of the disease to ensure reinforcement.

- Preparation of an instructional booklet to include the self-care interventions for older adults with HF. Taking into consideration criteria of written materials for the elders should be considered.

- Further researches are needed such as: effectiveness of nursing intervention strategies on the QOL of older adults with HF. 
Table (1): Relation between the socio-demographic characteristics and the mean quality of life of the study subjects prior to the interventions

\begin{tabular}{|c|c|c|c|}
\hline $\begin{array}{l}\text { Socio-demographic } \\
\text { characteristics }\end{array}$ & $\begin{array}{c}\text { Quality of life of the } \\
\text { study subjects }\end{array}$ & Statistical test & $P$ value \\
\hline $\begin{array}{l}\text { Age (in years): } \\
60- \\
65- \\
70 \text { and more }\end{array}$ & $\begin{array}{l}34.77 \pm 12.364 \\
40.75 \pm 12.612 \\
41.00 \pm 11.347\end{array}$ & $\mathrm{~F}=0.935$ & 0.405 \\
\hline $\begin{array}{l}\frac{\text { Sex }}{\text { Male }} \\
\quad \text { Female }\end{array}$ & $\begin{array}{l}38.09 \pm 12.943 \\
38.63 \pm 10.239\end{array}$ & $\mathrm{~F}=0.011$ & 0.917 \\
\hline $\begin{array}{l}\text { Marital status } \\
\text { Married } \\
\text { Widow }\end{array}$ & $\begin{array}{c}38.18 \pm 11.539 \\
39.31 \pm 3.300\end{array}$ & $\mathrm{~F}=0.001$ & 0.997 \\
\hline $\begin{array}{c}\text { Level of education } \\
\text { Read and write } \\
\text { Basic education } \\
\text { Secondary } \\
\text { University }\end{array}$ & $\begin{array}{l}40.25 \pm 10.90 \\
41.17 \pm 16.57 \\
36.69 \pm 8.29 \\
37.43 \pm 16.30\end{array}$ & $\mathrm{~F}=0.216$ & 0.885 \\
\hline $\begin{array}{l}\text { Occupation prior to retirement } \\
\text { Employee } \\
\text { Worker }\end{array}$ & $\begin{array}{l}37.55 \pm 13.20 \\
39.60 \pm 0.069\end{array}$ & $\mathrm{t}=0.431$ & 0.670 \\
\hline $\begin{array}{c}\frac{\text { Income }}{<} \text { (in pounds): } \\
500 \\
500- \\
1000+\end{array}$ & $\begin{array}{l}38.33 \pm 6.60 \\
39.38 \pm 11.94 \\
35.88 \pm 15.05\end{array}$ & $\mathrm{~F}=0.211$ & 0.811 \\
\hline
\end{tabular}

*Significant at $\mathrm{p} \leq 0.05$. 
Table (2): Relation between quality of life, self-care knowledge, and practice of the study subjects prior to the interventions

\begin{tabular}{|l|c|c|c|c|c|}
\hline Variables & $\begin{array}{c}\text { Self-care } \\
\text { practice }\end{array}$ & $\begin{array}{c}\text { Quality of } \\
\text { life }\end{array}$ & $\begin{array}{c}\text { Self-care } \\
\text { knowledge }\end{array}$ & Statistical test & P value \\
\hline $\begin{array}{l}\text { Self-care } \\
\text { knowledge }\end{array}$ & & & $\begin{array}{c}\text { Pearson } \\
\text { correlation } \\
=0.128\end{array}$ & 0.501 \\
\hline $\begin{array}{l}\text { Self-care } \\
\text { practice }\end{array}$ & & & & $\begin{array}{c}\text { Pearson } \\
\text { correlation } \\
=0.515\end{array}$ & $0.004^{*}$ \\
\hline & & & $\begin{array}{c}\text { Pearson } \\
\text { correlation } \\
=0.006\end{array}$ & 0.973 \\
\hline
\end{tabular}

*Significant at $\mathrm{p} \leq 0.05$.

Table (3): Effect of self-care interventions on the mean quality of life of older adults with heart failure

\begin{tabular}{|c|c|c|}
\hline Quality of life & $\begin{array}{c}\text { Immediate post test } \\
M=25.80 \pm 9.038\end{array}$ & $\begin{array}{l}\text { Before the } \\
\text { interventions }\end{array}$ \\
\hline $\begin{array}{l}\text { Before the interventions (pretest) } \\
\mathrm{M} \pm \mathrm{SD}=38.23 \pm 12.111\end{array}$ & $\begin{array}{l}\mathrm{T}_{1}=9.359 \\
\mathrm{P}=0.000^{*}\end{array}$ & \\
\hline $\begin{array}{l}6 \text { weeks after the interventions }(6 \mathbf{w} \\
\text { posttest) } \\
\mathrm{M}+\mathrm{SD}=28.13 \pm 8.541\end{array}$ & $\begin{array}{c}\mathrm{T}_{2}=0.938 \\
\mathrm{P}=0.359 \\
\mathrm{X}_{1}^{2}=30.71 \\
\mathrm{P}=0.000^{*}\end{array}$ & \\
\hline $\begin{array}{l}12 \text { weeks after the interventions }(12 \text { w } \\
\text { posttest) } \\
M \pm+S D=33.97+8.892\end{array}$ & $\begin{array}{c}\mathrm{T}_{3}=6.846 \\
\mathrm{P}=0.000^{*} \\
\mathrm{X}_{2}^{2}=44.616 \\
\mathrm{P}=0.000^{*}\end{array}$ & $\begin{array}{l}\mathrm{T}_{4}=3.851 \\
\mathrm{P}=0.001^{*}\end{array}$ \\
\hline
\end{tabular}

*Significant at $\mathrm{p} \leq 0.05$. 
Table (4): Effect of self-care interventions on mean self-care practices of older adults with heart failure

\begin{tabular}{|c|c|c|}
\hline Self-care practices & $\begin{array}{c}\text { Immediate post test } \\
M=18.20 \pm 2.413\end{array}$ & $\begin{array}{c}\text { Before the } \\
\text { interventions }\end{array}$ \\
\hline $\begin{array}{l}\text { Before the interventions (pretest) } \\
\mathrm{M} \pm \mathrm{SD}=10.20 \pm 3.326\end{array}$ & $\begin{array}{l}\mathrm{T}_{1}=15.837 \\
\mathrm{P}=0.000^{*}\end{array}$ & \\
\hline $\begin{array}{l}6 \text { weeks after the interventions }(6 \mathbf{w} \\
\text { posttest) } \\
M \pm S D=17.83 \pm 2.71\end{array}$ & $\begin{array}{c}\mathrm{T}_{2}=0.0628 \\
\mathrm{P}=0.535 \\
\mathrm{X}^{2}{ }_{1}=44.99 \\
\mathrm{P}=0.000^{*}\end{array}$ & \\
\hline $\begin{array}{l}12 \text { weeks after the interventions }(12 \mathrm{w} \\
\text { posttest) } \\
\mathrm{M} \pm \mathrm{SD}=13.70 \pm 2.842\end{array}$ & $\begin{array}{c}\mathrm{T}_{3}=8.649 \\
\mathrm{P}=0.000^{*} \\
\mathrm{X}_{2}^{2}=71.458 \\
\mathrm{P}=0.000^{*}\end{array}$ & $\begin{array}{l}\mathrm{T}_{4}=7.032 \\
\mathrm{P}=0.000^{*}\end{array}$ \\
\hline
\end{tabular}

*Significant at $\mathrm{p} \leq 0.05$.

Table (5): Effect of self-care interventions on mean self-care knowledge of older adults with heart failure

\begin{tabular}{|c|c|c|}
\hline Self-care knowledge & $\begin{array}{c}\underline{\text { Immediate post test }} \\
M=9.01 \pm 1.179\end{array}$ & $\begin{array}{c}\text { Before the } \\
\text { interventions }\end{array}$ \\
\hline $\begin{array}{l}\text { Before the interventions (pretest) } \\
\mathrm{M} \pm \mathrm{SD}=5.23 \pm 1.25\end{array}$ & $\begin{array}{l}\mathrm{T} 1=1.380 \\
\mathrm{P}=0.072\end{array}$ & \\
\hline $\begin{array}{l}\text { 6 weeks after the interventions }(6 \mathbf{~ w} \\
\text { posttest) } \\
M \pm S D=8.07 \pm 1.251\end{array}$ & $\begin{array}{c}\mathrm{T} 2=14.226 \\
\mathrm{P}=0.178 \\
\mathrm{X} 21=47.62 \\
\mathrm{P}=0.213\end{array}$ & \\
\hline $\begin{array}{l}12 \text { weeks after the interventions }(12 \mathrm{w} \\
\text { posttest) } \\
M \pm S D=5.70 \pm 1.69\end{array}$ & $\begin{aligned} \mathrm{T} 3 & =6.643 \\
\mathrm{P} & =0.79 \\
\mathrm{X} 22 & =69.138 \\
\mathrm{P} & =0.114\end{aligned}$ & $\begin{array}{l}\mathrm{T}_{4}=4.704 \\
\mathrm{P}=0.192\end{array}$ \\
\hline
\end{tabular}

*Significant at $\mathrm{p} \leq 0.05$. 
Table (6): Effect of the self-care interventions on mean quality of life and health status of the study subjects

\begin{tabular}{|c|c|c|c|c|}
\hline Health status & $\begin{array}{l}\text { QOL pre the } \\
\text { interventions }\end{array}$ & $\begin{array}{c}\text { QOL } \\
\text { immediately } \\
\text { after the } \\
\text { interventions }\end{array}$ & \begin{tabular}{|c|} 
QOL 6 wk. \\
after the \\
interventions
\end{tabular} & $\begin{array}{l}\text { QOL } 12 \text { wk. } \\
\text { after the } \\
\text { interventions }\end{array}$ \\
\hline $\begin{array}{l}\text { Duration of being } \\
\text { diagnosed with } \mathbf{H F} \\
<5 \text { years } \\
5-\end{array}$ & $\begin{array}{c}34.50 \pm 12.655 \\
43.83 \pm 9.064 \\
\mathrm{~T}=2.201 \\
\mathrm{P}=0.038^{*}\end{array}$ & $\begin{array}{c}24.22 \pm 9.89 \\
28.17 \pm 7.40 \\
\mathrm{~T}=1.179 \\
\mathrm{P}=0.248\end{array}$ & $\begin{array}{c}28.72 \pm 9.386 \\
27.25 \pm 7.399 \\
\mathrm{~T}=0.456 \\
\mathrm{P}=0.652\end{array}$ & $\begin{array}{c}32.06 \pm 10.418 \\
36.83 \pm 5.078 \\
T=1.471 \\
P=0.153\end{array}$ \\
\hline $\begin{array}{l}\text { (NYHA) classification } \\
\text { First class } \\
\text { Second class } \\
\text { Third class }\end{array}$ & $\begin{array}{c}23.29 \pm 6.184 \\
37.00 \pm 9.333 \\
47.23 \pm 7.120 \\
\mathrm{~F}=21.907 \\
\mathrm{P}=0.000 *\end{array}$ & $\begin{array}{c}17.71 \pm 5.122 \\
23.80 \pm 8.76 \\
31.69 \pm 6.89 \\
F=9.023 \\
P=0.001 *\end{array}$ & $\begin{array}{c}29.29 \pm 8.401 \\
29.10 \pm 8.962 \\
26.78 \pm 786 \\
F=0.279 \\
P=0.759\end{array}$ & $\begin{array}{c}25.14 \pm 9.788 \\
32.90 \pm 7.96 \\
39.54 \pm 3.950 \\
F=9.722 \\
P=0.001 * \\
\end{array}$ \\
\hline $\begin{array}{l}\text { Number of medical } \\
\text { diseases } \\
2 \\
3 \\
4 \text { and more }\end{array}$ & $\begin{array}{c}27.20 \pm 11.96 \\
35.43 \pm 9.693 \\
49.51 \pm 11.50 \\
F=2.026 \\
P=0.077\end{array}$ & $\begin{array}{c}17.00 \pm 3.08 \\
24.83 \pm 11.68 \\
32.75 \pm 9.14 \\
F=1.811 \\
P=0.141\end{array}$ & \begin{tabular}{|c|}
$25.20 \pm 7.259$ \\
$28.67 \pm 12.055$ \\
$36.00 \pm 6.245$ \\
$\mathrm{~F}=0.865$ \\
$\mathrm{P}=0.535$ \\
\end{tabular} & $\begin{array}{c}34.67 \pm 2.517 \\
31.00 \pm 8.583 \\
41.00 \pm 4.243 \\
F=2.098 \\
P=0.093\end{array}$ \\
\hline $\begin{array}{l}\text { Number of current } \\
\text { prescribed medications } \\
\text { consumed } \\
3 \\
4 \\
5 \text { and more }\end{array}$ & $\begin{array}{c}28.88 \pm 9.761 \\
37.00 \pm 9.899 \\
46.21 \pm 9.18 \\
\mathrm{~F}=3.066 \\
\mathrm{P}=0.013^{*}\end{array}$ & $\begin{array}{c}18.25 \pm 4.83 \\
23.71 \pm 10.56 \\
30.75 \pm 6.38 \\
F=3.032 \\
P=0.029 *\end{array}$ & \begin{tabular}{|c|}
$19.75 \pm 5.188$ \\
$26.50 \pm 2.121$ \\
$32.29 \pm 10.226$ \\
$F=1.262$ \\
$P=0.311$
\end{tabular} & $\begin{array}{c}28.50 \pm 0.07 \\
37.25 \pm 7.632 \\
39.63 \pm 3.583 \\
F=2.636 \\
P=0.049^{*}\end{array}$ \\
\hline $\begin{array}{l}\text { Hospitalization in the } \\
\text { last year } \\
\text { No } \\
\text { One time } \\
\text { Two times } \\
3 \text { and more }\end{array}$ & $\begin{array}{c}28.00 \pm 14.408 \\
35.00 \pm 10.315 \\
39.00 \pm 9.899 \\
52.00 \pm 2.828 \\
\mathrm{~F}=2.861 \\
\mathrm{P}=0.041 *\end{array}$ & $\begin{array}{c}20.67 \pm 8.091 \\
19.67 \pm 6.91 \\
38.33 \pm 9.07 \\
36.00 \pm 1.414 \\
F=2.131 \\
P=0.075\end{array}$ & \begin{tabular}{|c}
$25.17 \pm 7.808$ \\
$30.50 \pm 10.134$ \\
$29.50 \pm 2.121$ \\
$30.00 \pm 13.52$ \\
$F=0.548$ \\
$P=0.821$
\end{tabular} & $\begin{array}{c}32.33 \pm 8.892 \\
31.60 \pm 5.683 \\
33.50 \pm 7.77 \\
41.00 \pm 4.243 \\
F=1.44 \\
P=0.235\end{array}$ \\
\hline
\end{tabular}

*Significant at $\mathrm{p} \leq 0.05$.

QOL: quality of life 
Table (7): Effect of the self-care interventions on the quality of life and the self-care practices and self-care knowledge of the study subjects

\begin{tabular}{|c|c|c|c|c|}
\hline $\begin{array}{l}\text { Self-care practice } \\
\text { and knowledge }\end{array}$ & $\begin{array}{l}\text { QOL pre the } \\
\text { interventions }\end{array}$ & $\begin{array}{c}\text { QOL } \\
\text { immediately } \\
\text { after the } \\
\text { interventions }\end{array}$ & $\begin{array}{c}\text { QOL } 6 \text { wk. } \\
\text { after the } \\
\text { interventions }\end{array}$ & $\begin{array}{l}\text { QOL } 12 \text { wk. } \\
\text { after the } \\
\text { interventions }\end{array}$ \\
\hline Self-care practice & $\begin{array}{c}\text { Pearson } \\
\text { correlation } \\
=0.515 \\
\mathrm{P}=0.004^{*}\end{array}$ & $\begin{array}{c}\text { Pearson } \\
\text { correlation } \\
=0.155 \\
\mathrm{P}=0.415\end{array}$ & $\begin{array}{c}\text { Pearson } \\
\text { correlation } \\
=0.171 \\
\mathrm{P}=0.365\end{array}$ & $\begin{array}{c}\text { Pearson } \\
\text { correlation } \\
=0.441 \\
\mathrm{P}=0.015^{*}\end{array}$ \\
\hline $\begin{array}{l}\text { Self-care } \\
\text { knowledge }\end{array}$ & $\begin{array}{c}\text { Pearson } \\
\text { correlation } \\
=0.006 \\
\mathrm{P}=0.973\end{array}$ & $\begin{array}{c}\text { Pearson } \\
\text { correlation }= \\
0.389 \\
\mathrm{P}=0.341\end{array}$ & $\begin{array}{c}\text { Pearson } \\
\text { correlation }= \\
0.199 \\
\mathrm{P}=0.291\end{array}$ & $\begin{array}{c}\text { Pearson } \\
\text { correlation } \\
=0.069 \\
\mathrm{P}=0.717\end{array}$ \\
\hline
\end{tabular}

*Significant at $\mathrm{p} \leq 0.05$.

QOL: quality of life 


\section{References}

1. Jaarsma $T$, Halfens $H$, Huijer $K$, Dracupc J, Stappersb J, Van R. Quality of life in older patients with systolic and diastolic heart failure. Eur J Heart Fail 1999; 1 (2): 151-160.

2. Department of Health. National Service Framework: Coronary Heart Disease, HMSO, London, 2000.

3. Happ M, Naylor M, Roe-Prior P. Factors contributing to rehospitalization of elderly patients with heart failure. J Cardiovasc Nurs 1997; 11:75-84.

4. Ibrahim M. Heart failure manual: Egyptian hypertensive society guidelines. Egypt: Aventis Egypt 2000.

5. Hobbs F, Kenkre J, Roalfe A, Davis R, Hare R, Davies K. Impact of heart failure and left ventricular systolic dysfunction on quality of life. Eur Heart J 2002; 23: 1867-76.

6. Murphy N, Simpson C, Alister F. National survey of the prevalence, incidence, primary care burden, and treatment of heart failure in Scotland. Heart 2004; 90: 1129-36.

7. National Collaborating Centre for Chronic Conditions. Chronic heart failure. National clinical guideline for diagnosis and management in primary and secondary care. London: National Institute for Clinical Excellence (NICE), 2003.

8. Riegel B, Carlson B, Glaser D. Development and testing of a clinical tool measuring self-management of heart failure. Heart \& Lung 2002; 29(1): 4-15.

9. Mehta P, Dubrey S, McIntyre H, Walker D, Hardman S, Sutton G, Donagh T, Cowie M. Improving survival in the 6 months after diagnosis of heart failure in the past decade: population-based data from the UK. Heart 2009; 95:1851-56.
10. Liou H, Lee S, Hsu S. Factors related to self-care in heart failure patients. Heart \& Lung 2010; 57(2): 99-104.

11. Julie M. Factors affecting self-care in heart failure: A literature review. British Journal of Cardiac Nursing 2008; 3(7): 293 - 99.

12. Martenssona A, Stromberge U, Dahlströme E. Karlssona B, Fridlundb G. Patients with heart failure in primary health care: effects of a nurse-led intervention on health-related quality of life and depression. European Journal of Heart Failure 2004; 7 (3): 393-403.

13. Jones A, O'Connell J, Gray C. Living and dying with congestive heart failure: addressing the needs of older congestive heart failure patients. Age Ageing 2003; 32: $566-78$.

14. Linton A, Lach H. Gerontological Nursing: concepts and practice. $3^{\text {rd }}$ ed. USA: Elsevier Inc., 2007; 939-61.

15. Meiner S. Gerontological nursing. $4^{\text {th }}$ ed. USA: Mosby Co., 2009.

16. Heart Failure Society of America. The Stages of Heart Failure-NYHA Classification; 2002. Available at: http://abouthf.org/questions stages.htm. Retrieved on 10/8/2010. [Cited 2003 Oct. 31].

17. Folstein $J$, Folstein $S$, MCHugh $R$. Minimental state: a practical method of grading the cognitive state of patients for the clinician. Journal of Psychiatric Research 1975; 12: 189-95.

18. Elhusseini S. Factors related to self care capabilities among institutionalized elders. Unpublished Master Thesis, Faculty of Nursing, Alex University, 2008.

19. Yesavage A, Brink L, Rose L, Lum O, Huang V, Adey B, Leirer O. Development and validation of a geriatric depression screening scale: A preliminary report. Journal of Psychiatric Research 1983; 17(1): 37-49. 
20. Rector T, Cohn J. Assessment of patient outcome with the Minnesota Living with Heart failure Questionnaire: Reliability and validity during a randomized double blain, placebo-controlled trail of Pimobentin. Am Heart J 1992; 124: 1017-25.

21. Jaarsma T, Stromberg A, Martensson J, Dracup K. Development and testing of the European Heart Failure Self-Care Behaviour Scale. European Journal of Heart Failure, 2003; 2 (5), 363-70.

22. Vander Wal H, Jaarsma T, Moser K and Van Veldhuisen J. Development and testing of the Dutch Heart Failure Knowledge Scale. European Journal of Cardiovascular Nursing. 2005; 4(4), 27377.

23. Minino A, Arias E, Kochanek K, Murphy S, Smith B. Deaths: final data for 2000, National Vital Statistics Reports (vol50), national vital statistics system, 2002.

24. Lloyd-Jones D, Adams R, Carnethon M. Heart disease and Stroke Statistics 2009 Update. A report from the American Heart Association Statistics Committee and Stroke Statistics Subcommittee. Circulation 2009; 119: e21-e181.

25. Chin M, Goldman L. Gender differences in 1-year survival and quality of life among patients admitted with congestive heart failure. Med care 1999; 36: 1033-1046.

26. Clark R, McLennan S, Dawson A. Uncovering a hidden epidemic: a study of the current burden of heart failure in Australia. Heart Lung Circ 2004; 13: 26673.

27. Najafi F, Dobson A, Jamrozik K. Recent changes in heart failure hospitalizations in Australia. Eur J Heart Fail 2007; 9: 22833.

28. Konstam V, Salem D, Gorkin L, Pouleur $\mathrm{H}$. Base line quality of life as a predictor of mortality and hospitalization in patients with congestive heart failure. SOLVD
Investigations. Studies of LT ventricular dysfunction investigators. Am J Cardiol 2006; 78: 890-95.

29. Ekman I, Fagerberg B, landman B. Health related quality of life and sense of coherence among elderly patients with severe chronic heart failure in comparison with healthy controls. Heart lung 2002; 31 : 94-101.

30. Zamroskie C, Noser D, Bahat G, Zeigler C. Impact of symptoms prevalence and symptoms burden on patients with heart failure. European Journal of Cardiac Nursing 2005; 4: 198-206.

31. Hou N, Chui M, Eckert J, Oldridge N, Murray D, Bennett J. Relationship of age and sex to health-related quality of life in patients with heart failure. American Journal of Critical Care 2004; 13(2): 15361.

32. De Jong M, Riegel B, Armola R, Moser D. Trajectory ofquality of life in heart failure patients with preserved and non preserved systolic function. American Journal of Critical Care 2006; 15(3): 324-25.

33. Abd El Ghaffar A. Factors affecting selfcare practices of cardiac patients in Alexandria. Unpublished Master thesis, faculty of Nursing, Alexandria University, 2003; 49-59.

34. Elshazly S. Health promotion of the elderly. Review article, the permanent scientific committee of nursing 2001: 4-8, 29-42.

35. Artinian T, Magnan M, Sloan M, Lange P. Self-care behaviors among patients with heart failure. Heart and Lung: Journal of Acute and Critical Care 2002; 31(3): 161172.

36. Lee D, Woo J, Thompson R. Health-related quality of life in patients with congestive heart failure. The European Journal of Chronic Heart Failure 2005; 7: 419- 22. 
37. Zeleznink D. Self-care of the home dwelling elderly people living in Slovenia. Doctorate dissertation, Faculty of Medicine, Oulu University, 2007: 79-83.

38. Heo S, Moser D, Chung M, Lennie T. Social status, health related quality of life, and event - free survival in patients with heart failure. Eur J Cardiovasc Nurs 2012; 11(2): 141- 49

39. Hoe S. A review of the literature on health related quality of life in patients with heart failure: definition, measurement, and related variables, in Lexington, KY, 2004.

40. Stewart S. Recognising the "other half" of the heart failure equation: are we doing enough for family caregivers? Eur J Heart Fail 2005; 7: 590-91.

41. Carlson B, Riegel B. Self care abilities of patients with heart failure. Heart lung Journal of Critical Care; 30: 351-359.

42. Jaarsma T, Halfen R, Abusaad H. Self care and quality of life in patients with advanced heart failure. The effect of supportive educational interventions. Heart lung Journal of Critical Care 2001; 29: 319-330

43. Rich M, Beckham V, Wittenbereg C. A multidisciplinary intervention to prevent the readmission of elderly patients with congestive heart failure. The New England $\mathrm{J}$ of Medicine 2008; 333: 1190-95.

44. House-faucher M, Martinez L. Medical surgical nursing: nursing management: congestive heart failure and cardiac surgery. $5^{\text {th }}$ ed. St. Louis: Mosby 2000: 889- 907.

45. Driscoll A, Davidson P, Clark R, and Huang N. Tailoring consumer resources to enhance self-care in chronic heart failure. Australian Critical Care 2009; 22: 133-40.
46. Ni H, Nauman D, Burgess D, Wise K, Crispell K, Hershberger R. Factors influencing knowledge of and adherence to self-care among patients with heart failure. Archives of Internal Medicine 1999; 159: 1613- 19.

47. Gaze C. The role of existing and novel cardiac biomarkers for cardio-protection. Current Opinion in Investigational Drugs 2007; 8(9): 711-17.

48. Yu D, Thompson D, and Lee D. Disease management programs for older people with heart failure: crucial characteristics which improve post discharge outcomes. Eur Heart J 2006; 27 (5): 596-612.

49. Heart Failure Society of America (HFSA). HFSA 2006 comprehensive heart failure practice guidelines. J Card Fail 2006; 12 (1): e1-e2.

50. Kutzleb J, Reiner D. The impact of nurse directed health education on quality of life and functional capacity in people with heart failure. J Am Acad nurse Pract 2006; 18 (3): 116-123.

51. Haynes R, Yao X, Degani A, Kripalanis, Garg A, McDonald $\mathrm{H}$. Interventions to enhance medication adherence. Cochrane data base Syst Rev, 2005 (4): CD000011.

52. Norris $S$, Engelgau $M$, Narayan $M$. Effectiveness of self-management training in type 2 diabetes: a systematic review of randomized controlled trials. Diabetes Care2001: 24; 561-87.

53. Geoffrey R. Evaluating Forgetting Curves. Journal of Experimental Psychology: Learning, Memory, and Cognition 1985: 11(2); 397- 406. 